Research Article

\title{
Effect of Organizational Cultural Differences and Mutual Trust on Contract Management of Nonequity Construction Project Alliances
}

\author{
Yanling Zhao $\mathbb{D},{ }^{1}$ Yingbin Feng, ${ }^{2}$ and Chenggang $\mathrm{Li}^{3}$ \\ ${ }^{1}$ School of Construction Management and Real Estate, Chongqing University, Chongqing 400045, China \\ ${ }^{2}$ School of Computing, Engineering and Mathematics, Western Sydney University, Penrith, NSW 2751, Australia \\ ${ }^{3}$ Chongqing Public Resources Trading Center, Chongqing 40014, China
}

Correspondence should be addressed to Yanling Zhao; cquzhyl@126.com

Received 7 December 2017; Accepted 23 January 2018; Published 4 March 2018

Academic Editor: Michael Yam

Copyright (C) 2018 Yanling Zhao et al. This is an open access article distributed under the Creative Commons Attribution License, which permits unrestricted use, distribution, and reproduction in any medium, provided the original work is properly cited.

This study aims to examine the impact of organizational cultural difference and mutual trust on the contract management of nonequity project alliances in the construction industry. A questionnaire survey was conducted to collect the quantitative data for this study. The relationships between the variables were analyzed using hierarchical regression analysis. It was found that the contractual complexity of nonequity project alliances was impacted by the differences in management style, differences in organizational responsiveness, mutual goodwill trust, and mutual competence trust. It was also found that the relationship between differences in organizational responsiveness and contractual complexity was moderated by mutual goodwill trust. The research may provide theoretical basis for the management when making decisions on the selection of project alliance partners and contracts. The findings imply that when the firms seek to form project alliances, they need to recognize the level of organizational cultural differences and then determine the proper contractual complexity of the project alliance. In addition, the establishment of mutual goodwill trust between alliance partners will not only reduce the costs of making contracts but also the costs of implementing the contracts.

\section{Introduction}

The construction project relies on a high proportion of small- and medium-sized enterprises which are involved in off-site manufacturing (e.g., design and procurement) and on-site production (e.g., assembly and supporting services) [1]. Higher number of market participants tends to increase transaction costs and reduce management efficiency [2]. In the meantime, increasingly more construction companies were involved in alliances (e.g., the alliances of client, design, and construction companies) to deal with increasingly intense market competition, complex construction technologies and diversified client requirements [3]. An alliance is a form of relationship contracting in which the establishment and management of relationships between partners may remove barriers and maximize partners contributions and success [4]. Cobianchi [5] found that the success of alliances is positively related to the geographical, cultural, and environmental similarity of the project alliance participants. Negligence of the participants' organizational cultural differences is one of the most frequently cited causes of the failure of alliances (e.g., $[3,6]$ ).

Some researchers argued that proper modes of contract management can be used to balance the benefits of participants, maximize the chance of success for project, and improve the performance of project [7-9]. In general, project alliances are divided into equity alliances and nonequity alliances $[10,11]$. Nonequity alliances, which do not involve share proportion relations, are more popular in the construction project than equity alliances. The collaboration of nonequity alliance partners is mainly reflected by the alliance contract, which specifies the scope of collaboration, the rights and obligations of partners, and the way of resolving disputes [12]. Reuer and Ariño [12] further argued that more complex 
negotiation and enforcing contracts may be avoided when the risk of opportunistic behaviors decrease. Contractual complexity can be used to reflect the degree of cooperation between alliance partners and the degree of constraints applied to the behaviors of alliance partners as the contractual contents include the terms of conditions and coordination [13].

Rodriguez [14] indicated that the alliance partners need to adjust their organizational cultures or cultivate a common culture to improve alliance performance. When there are significant cultural differences, most firms tend to choose integration of partners rather than nonequity alliances [15]. For the nonequity alliances which are popular in the construction industry, it is still unclear whether the cultural differences will have impact on the contractual complexity of an alliance.

Furthermore, China appears to be a country of low credit. However, it has been found that high-level trust exists among families, acquaintances, and friends in the Chinese society. "GuanXi," which describes relationships that may result in the exchanges of favors or "connections" that are beneficial for the parties involved, is an important characteristic of the Chinese business environment [16]. When forming the alliances, the selection of partners is not strictly based on the assessment of a large number of potential partners according to the targets of the alliance, but rather directly targets some particular organizations with "GuanXi." "GuanXi" is embodied in the trust between members of the alliance. The trust of cooperative partners may, to some extent, reduce the transaction risks of the partners and influence the choice of alliance contracts [17]. The traditional evaluation of trust is based on single-sided judgement and reflects single-sided willingness [18]. However, if both parties have different evaluations on trust, the traditional evaluation may not be able to reflect the impact of trust on the performance and risks of alliances. Thus, it seems necessary to develop the mutual trust, which represents both parties' mutual judgement on the alliance organizational trust [18]. Das and Teng [19, 20] pointed out that the goodwill trust and competence trust are the two independent dimensions of trust. Therefore, the mutual trust in the context of Chinese society is classified into mutual goodwill trust and mutual competence trust. This study aims to investigate the interactive effects of the two types of mutual trust and cultural differences on the contractual complexity of construction alliances.

\section{Theoretical Background and Hypotheses}

2.1. Organizational Cultural Differences and Contractual Complexity. Organizational culture consists of two aspects: (1) management style and (2) organizational response [15]. Management style comprises the management attitudes towards risks and their methods of decision making, control, and communication [21]. Some firms rely on formal rules and regulations and strict control, whilst other companies prefer flexibility and employees involvement in decisionmaking. Individual organizations tend to have their distinct management styles. Significant differences in the management styles of the alliance partners are likely to cause problems in communication and conflicts between the partners. This will bring about higher transaction risks to the organizations and alliance. To avoid such risks, the alliance tends to use complex contractual arrangements to regulate the partners' behaviors [22]. Written bespoke contracts are signed by all the partners [23] to avoid potential misinterpretations that may affect the alliance relationship [24]. Therefore, the following hypothesis was postulated:

Hypothesis 1. The contractual complexity of an alliance is affected by the differences in management style.

Organizational response is another aspect of organizational culture. It refers to the company's responses to the external enterprises and environments [25]. Different organizational members tend to have different attitudes towards external environments. Some companies prefer independent operation, while others prefer to establish close relationship with external organizations. The inconsistence of the alliance partners' responses to external environment has a direct impact on the alliance governance [15]. For example, if a company is open-minded and tends to trust others but its partners are suspicious, the mutual willingness of both parties is not likely to be achieved. Collaboration requires exchange of attitudes and information [26]. The partners tend to become distrustful when they have different tendencies in sharing information and accepting others' advices. Moreover, when the partners have different attitudes towards the common stakeholders, such inconsistence may lead to malfunction of the alliance relationship. Similarly, inconsistent responses to incidents may result in mistrust. The alliance partners may refuse to make commitment and act independently if they expect that other partners will not act as expected. The above problems that are incurred by significant differences in organizational responsiveness may require complex contractual arrangements to regulate the behaviors of each party. Therefore, the second hypothesis is set out as following:

Hypothesis 2. The contractual complexity of an alliance is affected by the differences in organizational responsiveness.

\subsection{Mutual Trust and Contractual Complexity}

The concept of trust has two dimensions: (1) goodwill trust and (2) competence trust $[19,20]$. The mutual trust can be classified into mutual goodwill trust and mutual competence trust. Mutual goodwill trust refers to the belief of goodwill, responsible, and reliable trust between alliance partners [27]. To avoid the cooperation problems (e.g., communication and conflicts) incurred by the differences in management styles, the alliance partners tend to use complex contracts to regulate the behaviors of the participants and achieve the targets of cooperation. However, high level of mutual goodwill trust among the alliance partners may facilitate the information sharing and then effectively avoid conflicts [28]. Thus, the alliance partners with high level of mutual trust tend to reduce the reliance on complex contracts to save the contracting costs [28]. It is therefore likely that mutual goodwill trust may mitigate the distrust and conflicts resulted from organizations cultural differences. 


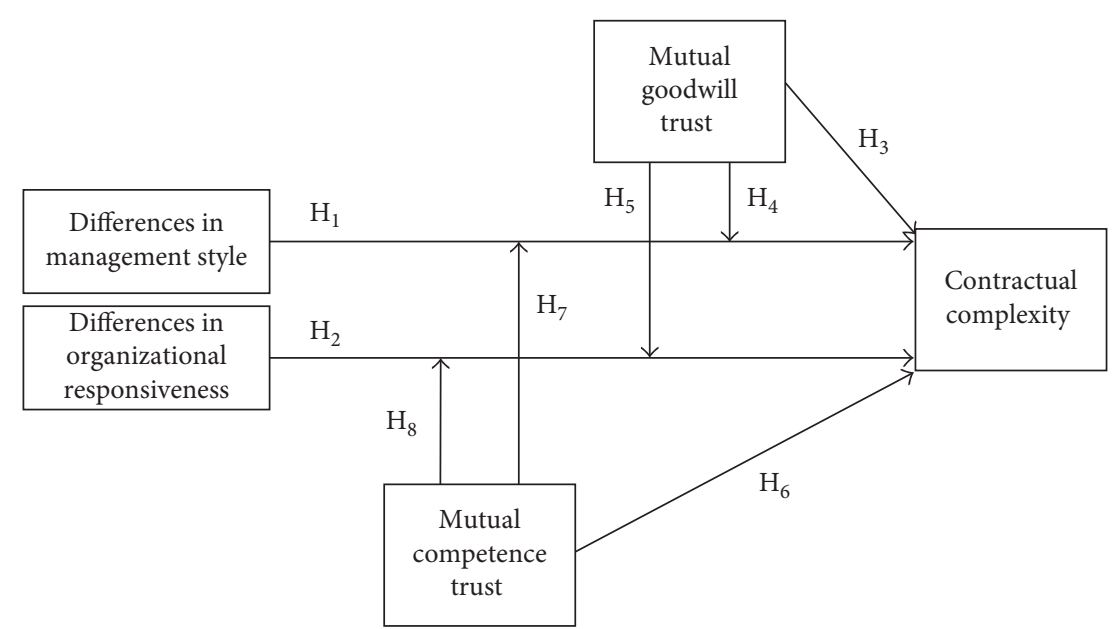

FIGURE 1: Conceptual model for the relationships between OCD, MT, and CC.

Hypothesis 3. The contractual complexity of an alliance is affected by mutual goodwill trust.

Hypothesis 4. The relationship between the differences in management style and the contractual complexity is moderated by mutual goodwill trust.

Hypothesis 5. The relationship between the differences in organizational responsiveness and the contractual complexity is moderated by mutual goodwill trust.

Competence trust focuses on the objective aspect of trust [20]. It relates to the belief of whether the partners will fulfill their commitments or not. For example, will the partners' activities and behaviors within the alliance be trusted? Do the partners have the claimed technologies and resources? Whether the partners will use these technologies and resources in the activities and operations of the alliance [20]? If a company believes that its partner can complete the work as expected under disadvantageous conditions, the company tends to expand the scope of cooperation, which will bring the risks of partners' opportunistic behaviors to the company [29]. Jiang [30] argued that if the companies trust their partners' competence in understanding and using new knowledge and techniques, they tend to adopt more defensive actions to reduce the risk of losses of core knowledge and techniques. However, if the companies trust their partners' competence, they are more likely to (1) accept the partners' suggestions and (2) accept the short-term losses based on their anticipation for the future performance [31]. The mutual competence trust may improve the communications between the partners and reduce the chance of conflicts. It is therefore likely that the relationship between organizations cultural differences and contractual complexity is moderated by the level of mutual competence trust.

Hypothesis 6. The contractual complexity of an alliance is affected by mutual competence trust.
Hypothesis 7. The relationship between the differences in management style and the contractual complexity is moderated by mutual competence trust.

Hypothesis 8. The relationship between the differences in organizational responsiveness and the contractual complexity is moderated by mutual competence trust.

The conceptual model based on the above hypotheses is described in Figure 1.

\section{Research Methods}

3.1. Measures. This study aims to explore the interrelationships between multiple variables, which indicates a correlational research study in nature. A questionnaire survey was conducted to collect the quantitative data for this study. The questionnaire was designed based on literature review, expert comments, and preliminary field study. The research variables were operationalized as follows.

3.1.1. Contractual Complexity (CC). The behaviors of alliance partners are confined by the contracts between all parties. The research on the alliance contracts can be traced back to the research by Parkhe [32], who listed out the contractual conditions, including (1) regularly report all the relevant transactions; (2) timely record notice of any departures from the agreement; (3) have the right to check and audit all the relevant records through chartered accountants; (4) some particular information or resources are restricted by Certified Public Accountants; (5) stop using proprietary information even after termination of agreement; (6) termination date; (7) arbitration clauses; and (8) lawsuit provisions. Following Reuer and Ariño [12] and Lumineau and Malhotra [13], the contractual complexity was calculated by the following formula:

$$
\text { contractual complexity }=\frac{1}{36} \sum D_{i},
$$


where $D_{i}(i=0,1, \ldots, 8)$ represents that the $i$ th clause was adopted, and zero otherwise.

3.1.2. Organizational Cultural Differences (OCD). In this study, organizational cultural differences include the differences in the partners' management styles (MD) and differences in organizational responsiveness (RD). Differences in the management style were measured by the following three scale items: (1) company/partner relies on informal organizations (e.g., with loose control and monitor) [15, 21, 33]; (2) company/partner's decision making relies on top management $[15,21,34]$; and (3) company/partner organization is open $[15,33,34]$. The organizational response differences were measured by the following 3 scale items: (1) company/partner trusts others (e.g., willing to share sensitive information) $[15,35]$; (2) company/partner uses an open approach to solve conflicts [36]; and (3) company/ partner is flexible $[15,37]$. In the questionnaire, the scale items for measuring the differences in management styles (MD) and differences in organizational responsiveness (RD) were rated using the 5-point Likert scale. Respondents were required to rate the scale items based on their perceptions about their company's organizational culture and the alliance partner's organizational culture. The organizational cultural differences were calculated using the following formula:

$$
\mathrm{OCS}=|\mathrm{OCC}-\mathrm{OCP}|
$$

where OCD represents the organizational cultural differences between the company and alliance partner; OCC represents the organizational culture of the company; and OCP represents the organizational culture of the alliance partner.

\subsubsection{Moderator-Mutual Trust (MT). Following Zaheer} et al. [38], goodwill trust and competence trust were measured using 4 scales and 3 scales, respectively. The mutual goodwill trust (MGT) includes the following: alliance partners are just in negotiation [29, 38, 39]; alliance partners are very reliable $[29,30,38]$; and alliance partners will act as expected [29, 38]. The mutual competence trust (MCT) comprises the following: alliance partners have good credit $[29,30,39]$; alliance partners have sufficient capital resources [29, 30, 39]; and alliance partners have sufficient human resources [29, 30, 39]. Following Huang et al. [18], the level of mutual goodwill trust can be calculated using the following formula:

$$
\mathrm{MT}=\mathrm{TF}+\mathrm{TP}-|\mathrm{TF}-\mathrm{TP}|,
$$

where MT represents mutual trust; TF represents trust of company; and TP represents trust of partner. The mutual trust is not only determined by the trust of both sides of alliance but also depends on the difference of trust of both sides.

3.1.4. Control Variables. Size differences (SD) may influence the stability of the alliance [40] and benefits allocation between partners [41]. Thus, SD was introduced as a control variable in this study. Size was measured by the number of employees. Prior relationship length (PRL) between the partners is likely to influence the degree of contractual details [42], and it was characterized by the duration of the prior relationship between the partners [13]. Asset specificity (AS) has a strong explanation power about the contractual governance $[9,43]$, and it was also introduced as a control variable. AS includes the following: the extent to which the resources are wasted after the termination of cooperation $[44,45]$; the extent to which the adjustments have been made during the operation $[45,46]$; and the time and capital required to train and evaluate collaborative partners [44, 47].

3.2. Sample and Data Collection. This study aims to investigate the issues regarding cooperation of project alliances; therefore, the respondents of the survey included the personnel who are familiar with the project alliance management. A screening question (i.e., are you familiar with the alliance management?) was included in the questionnaire to ensure that only the questionnaires completed by those who were familiar with alliance management were included in the subsequent data analysis. Before issuing the formal questionnaires, we conducted a pilot study in three construction firms who have experienced nonequity alliances. The questionnaires were completed by the top management personnel of the firms. Upon completion, respondents evaluated the contents of the questionnaire, understandability of questions and terminology, and proposed amendments. According to the feedback, we deleted the items that does not conform to the actual situation and amended the items that may cause confusions.

Simple random sampling methods were used to determine the sample for this study. Four hundred and eighty construction enterprises were randomly selected from the yellow pages of construction business in China and 320 construction enterprises were sourced through the research team's personal professional networks. The initial contact was made by telephone to request their participation in this research. The questionnaires were distributed to the participants by e-mail or post upon their agreement to participate in the research. A total of 580 construction enterprises agreed to participate in the survey and produced 202 valid questionnaires, thus yielding a valid response rate of $25 \%$. There is a big gap between the numbers of companies agreed to participate and valid questionnaires received in this survey. The main reasons may include the following: (1) the questionnaires completed by those who were not familiar with alliance management were excluded; (2) incomplete questionnaires were excluded; and (3) many companies who agreed to participate in this research failed to find suitable respondents or return the questionnaires in the required timeframe. The response rate was considered acceptable compared to the normal response rate of 20$30 \%$ reported in research of similar type in the construction industry [48-50]. 
TABLE 1: Descriptive statistics and correlations.

\begin{tabular}{|c|c|c|c|c|c|c|c|c|c|c|c|c|}
\hline Variables & Mean & Min. & Max. & $\mathrm{SD}$ & 1 & 2 & 3 & 4 & 5 & 6 & 7 & 8 \\
\hline 1. CC & 0.26 & 0.03 & 0.78 & 0.22 & 1 & - & - & - & - & - & - & - \\
\hline 2. $\mathrm{MD}$ & 2.60 & 1.00 & 3.33 & 0.51 & $0.48^{* *}$ & 1 & - & - & - & - & - & - \\
\hline 3. $\mathrm{RD}$ & 2.59 & 1.00 & 3.00 & 0.51 & $0.49^{* *}$ & $0.66^{* *}$ & 1 & - & - & - & - & - \\
\hline 4. MGT & 5.20 & 2.00 & 8.67 & 1.17 & $-0.22^{* *}$ & -0.09 & -0.09 & 1 & - & - & - & - \\
\hline 5. MCT & 5.34 & 2.67 & 8.67 & 1.17 & $0.28^{* *}$ & $0.15^{*}$ & $0.16^{*}$ & $0.41^{* *}$ & 1 & - & - & - \\
\hline 6. SD & 1.71 & 0.00 & 4.00 & 0.94 & $0.19^{* *}$ & 0.08 & 0.07 & 0.04 & 0.08 & 1 & - & - \\
\hline 7. PRL & 2.29 & 0.00 & 4.00 & 1.18 & 0.06 & -0.01 & -0.00 & -0.02 & -0.02 & 0.09 & 1 & - \\
\hline 8. AS & 2.54 & 1.00 & 3.33 & 0.53 & $0.39^{* *}$ & $0.51^{* *}$ & $0.40^{* *}$ & -0.10 & 0.10 & $0.16^{*}$ & -0.06 & 1 \\
\hline
\end{tabular}

\section{Result}

4.1. Test of Reliability and Validity. The data were analyzed using IBM SPSS Statistics 20 and IBM SPSS AMOS 20. Table 1 presents the descriptive statistics and the correlation coefficients between the research variables. The validity of the data collection instrument was assessed using Cronbach's alpha (>0.7) and CITC (corrected item-total correlation) $(>0.5)$ $[51,52]$. The internal factor structure of the questionnaire was assessed by unidimensionality test $(\mathrm{KMO}>0.7)$ [53]. Table 2 shows that the questionnaire has strong reliability and validity (Cronbach's $\alpha>0.7$; CITC $>0.5$ ). Moreover, the results of KMO $(>0.7)$ and Barlett test (significant) show that the questionnaire is suitable for factor analysis.

The questionnaire was designed based on the existing measure scales and the feedback from the pilot study. The scale items have been well recognized in prior studies and the pilot study, which indicates that the questionnaire has good contents validity. Construct validity was evaluated by assessing convergent validity and discriminant validity of constructs. Factor loadings $(>0.7)$, individual item reliability $(>0.5)$, composite reliability $(>0.8)$, and average variance extracted $(>0.5)$ tests were used to determine the convergent validity of measured construct. The square roots of the AVE of all the variables were higher than the correlation coefficients with other constructs, demonstrating the discriminant validity of constructs [54].

Table 3 shows that factor loadings, individual item reliability, CR, and AVE met the thresholds, indicating a satisfactory level of convergent validity. From Table 4, the square roots of AVE of all the variables were higher than the correlation coefficients with other constructs, demonstrating the discriminant validity of constructs.

4.2. Hierarchical Regression Analysis and Hypotheses Testing. Hierarchical regression analysis was used to test the hypotheses in this research. To test the effects of organizational cultural differences and mutual trust on contractual complexity and whether the relationship between organizational cultural differences and contractual complexity is moderated by mutual trust, three regression models were examined. The first model regressed CC on the control variables, namely, AS, PRL, and SD (Model 1 in Table 5). The
TABle 2: Reliability test.

\begin{tabular}{lccccc}
\hline Variable & Items & Indicator & CITC & $\begin{array}{c}\text { Cronbach's } \\
\text { alpha }\end{array}$ & $\begin{array}{c}\text { KMO (Barlett } \\
\text { test) }\end{array}$ \\
\hline \multirow{4}{*}{ AS } & 3 & AS1 & 0.674 & & \\
& & AS2 & 0.575 & 0.792 & $0.703^{* * * *}$ \\
& & AS3 & 0.654 & & \\
MD & 3 & MD1 & 0.748 & & \\
& & MD2 & 0.721 & 0.864 & $0.735^{* * *}$ \\
& & RD1 & 0.762 & & \\
RD & 3 & RD2 & 0.678 & & $0.701^{* * *}$ \\
& & RD3 & 0.788 & & \\
& & GT1 & 0.673 & & $0.700^{* * *}$ \\
MGT & 3 & GT2 & 0.761 & 0.832 & \\
& & GT3 & 0.645 & & $0.723^{* * *}$ \\
MCT & 3 & CT1 & 0.689 & & \\
& & CT2 & 0.718 & 0.851 & \\
\hline
\end{tabular}

${ }^{* * *} P<0.001$.

TABle 3: Convergent validity.

\begin{tabular}{llccc}
\hline Indicator & Loading & Reliability & AVE & CR \\
\hline AS1 & $0.773^{* * *}$ & 0.598 & & \\
AS2 & $0.735^{* * *}$ & 0.540 & 0.570 & 0.800 \\
AS3 & $0.757^{* * *}$ & 0.573 & & \\
MD1 & $0.832^{* * *}$ & 0.692 & & \\
MD2 & $0.790^{* * *}$ & 0.624 & 0.682 & 0.866 \\
MD3 & $0.855^{* * *}$ & 0.731 & & \\
RD1 & $0.718^{* * *}$ & 0.516 & & \\
RD2 & $0.739^{* * *}$ & 0.546 & 0.652 & 0.847 \\
RD3 & $0.946^{* * *}$ & 0.895 & & \\
MGT1 & $0.751^{* * *}$ & 0.564 & & \\
MGT2 & $0.911^{* * *}$ & 0.830 & 0.633 & 0.837 \\
MGT3 & $0.711^{* * *}$ & 0.506 & & \\
MCT1 & $0.758^{* * *}$ & 0.575 & & \\
MCT2 & $0.801^{* * *}$ & 0.642 & 0.659 & 0.853 \\
MCT3 & $0.873^{* * *}$ & 0.762 & & \\
\hline
\end{tabular}

${ }^{* * *} P<0.001$.

second model was developed by adding $\mathrm{MD}, \mathrm{RD}, \mathrm{MGT}$, and MCT to the regression analysis (Model 2 in Table 5). The last model (Model 3 in Table 5) was built by including the 
TABLE 4: Discriminant validity.

\begin{tabular}{lccccc}
\hline Variable & AS & MD & RD & MGT & MCT \\
\hline \multirow{2}{*}{ AS } & $0.570^{\mathrm{a}}$ & - & - & - & - \\
& $0.723^{\mathrm{b}}$ & - & - & - & - \\
\multirow{2}{*}{$\mathrm{MD}$} & $0.599^{\mathrm{c}}$ & 0.682 & - & - & - \\
& & 0.826 & - & - & - \\
\multirow{2}{*}{$\mathrm{RD}$} & 0.426 & 0.640 & 0.652 & - & - \\
& - & - & 0.808 & - & - \\
\multirow{2}{*}{ MGT } & -0.072 & -0.095 & -0.114 & 0.633 & - \\
& - & - & - & 0.796 & - \\
\multirow{2}{*}{ MCT } & 0.108 & 0.193 & 0.143 & 0.464 & 0.659 \\
& - & - & - & - & 0.812 \\
\hline
\end{tabular}

${ }^{a}$ Diagonal for variable AVE; ${ }^{b}$ square root AVE; ${ }^{c}$ diagonal external variable correlation coefficient.

TABLE 5: Hierarchical regression analysis.

\begin{tabular}{lccc}
\hline Variable & Model 1 & Codel 2 & Model 3 \\
\hline MD & - & $0.172^{*}$ & $0.174^{*}$ \\
RD & - & $0.238^{* * *}$ & $0.233^{* * *}$ \\
MGT & - & $-0.305^{* * *}$ & $-0.259^{* * *}$ \\
MCT & - & $0.320^{* * *}$ & $0.284^{* * *}$ \\
MD MGT & - & - & -0.066 \\
MD MCT & - & - & 0.117 \\
RD* MGT & - & - & $-0.162^{*}$ \\
RD ${ }^{*}$ MCT & - & - & 0.135 \\
AS & $0.372^{* * *}$ & $0.127^{*}$ & 0.112 \\
PRL & 0.071 & 0.059 & 0.045 \\
$\mathrm{SD}^{*}$ & 0.121 & $0.115^{*}$ & 0.086 \\
$\Delta \mathrm{R}^{2}$ & 0.170 & 0.109 & 0.039 \\
$\mathrm{R}^{2}$ & 0.170 & 0.428 & 0.467 \\
$\mathrm{~F}$ & $13.445^{* * *}$ & $20.620^{* * *}$ & $15.025^{* * *}$ \\
\hline$* * * P<0.001 ; * * P<0.01 ;{ }^{*} P<0.05$. & &
\end{tabular}

product terms (e.g., $\mathrm{MD} * \mathrm{MGT}, \mathrm{MD} * \mathrm{MCT}, \mathrm{RD} * \mathrm{MGT}$, and $\mathrm{RD} * \mathrm{MCT})$ in the regression analysis.

Before conducting the hierarchical regression analysis, the issues of multicollinearity and heteroscedasticity were tested. Results (VIF < 10 (3); DW close to 2 (1.6) [55]) show that there were no significant multicollinearity and heteroscedasticity issues. SPSS 20 was used to conduct hierarchical regression analysis. Variables were centered before testing the moderated effects [56]. The results of regression analysis are presented in Table 5.

The regression analysis of Model 4 (Table 5) shows that contractual complexity is positively related to the differences of management styles $(r=0.174)$, differences of organizational responsiveness $(r=0.233)$, and mutual competence trust $(r=0.284)$, whilst it is negatively related to mutual goodwill trust $(r=-0.259)$. The result provides evidence to support hypotheses 1 (i.e., CC is affected by MD), 2 (i.e., CC is affected by RD), 3 (i.e., CC is affected by MGT), and 6 (i.e., CC is affected by MCT).

The moderated effects of mutual trust on contractual complexity are analyzed by examining model 3 and model 4
(Table 5). The results show that $R^{2}$ of Model 4 was raised to 0.467 compared to that of Model 3, which indicates that Model 4 has a stronger explanation power than Model 3. Table 5 shows that the effects of the RD and MGT interaction term $(r=-0.162)$ on CC are significant $(P<0.05)$, which indicates that the relationship between $\mathrm{RD}$ and $\mathrm{CC}$ was moderated by MGT. The relationship between MD and CC was not significantly $(r=-0.066, P>0.05)$ moderated by the MGT. The relationship between MD and CC was not significantly $(r=0.117, P>0.05)$ moderated by the MCT. The relationship between $\mathrm{RD}$ and $\mathrm{CC}$ was not significantly $(r=0.135, P>0.05)$ moderated by the MCT. These results provide empirical evidence to support hypotheses 5 . However, hypotheses 4,7 , and 8 were not supported. The implications of the hypotheses testing results are discussed in the following section.

\section{Discussion}

The results of hypotheses testing show that contractual complexity is influenced by the differences in management style and organizational responsiveness. For the nonequity project alliance in the construction industry, similar organizational culture between the partners will facilitate the understanding, communication, and information sharing between them; therefore, alliance targets can be achieved without more complex contracts. On the other hand, more significant difference in management style and organizational response may lead to more difficulties in communications and higher possibility of conflicts between partners. The results support the existing research findings that the culture match and the success of alliances are positively correlated $[3,57]$ and that organizational cultural difference was viewed as one of the important factors influencing the project alliance contractual complexity. It establishes the relationship between the organizations' cultural difference and contractual complexity in the construction industry and expands the research on the relationship between organizational cultural difference and relational mechanisms [15]. As culture is difficult to change for all the alliance partners, they can only use complex alliance contracts to balance the relationships between all parties and minimize the risks of collaborations from organizations' cultural difference.

The results also show that contractual complexity is impacted by mutual goodwill trust and mutual competence trust. The complexity of contracts may be reduced with the increasing level of goodwill trust. Therefore, the value of goodwill trust should be emphasized no matter whether there are cultural differences between partners. Chinese people are more willing to partner with those who have "Guanxi" with them because there is a higher level of goodwill trust between them. The findings support the suggestion of Peter et al. [24] to establish goodwill trust between partners in the negotiation stage.

Mutual competence trust was found to have positive impact on contractual complexity of project alliances. The finding suggests that a higher level of mutual competence trust may result in more complex contracts. The following two possible reasons may explain why higher level of mutual 
competence trust tends to be associated with more complex contracts. First, higher level of mutual competence trust between partner means that they may have stronger capacity to implement the contracts; therefore, the anticipated partnership targets are likely to be achieved by setting out many aspects in the contracts without worrying about the partners' capacity to implement the contracts. Second, as suggested by [30], the partners with similar levels of competence are more likely to worry about the issue of knowledge stealing, which requires more constraints be specified in the contracts. Both aspects may lead to a higher level of contractual complexity.

The results of hierarchical regression analyses indicated that the relationship between differences in organizational responsiveness and contractual complexity was moderated by mutual goodwill trust. When there is a higher level of mutual goodwill trust between partners before entering the partnership, the partners may have good communications and less conflicts based on trust, goodwill, and kindness even if they have significant differences in organizational responsiveness, which involves the firm's attitudes toward external partners and the level of trust [15].

\section{Conclusions}

This study investigated the impact of organizations cultural difference on project alliance contractual complexity and the moderated role of mutual trust. Through the empirical analysis of a sample of 202 project alliances in the construction industry, the study found that the project alliance contractual complexity was influenced by differences in management style, differences in organizations response, mutual goodwill trust, and mutual competence trust. The relationship between differences in organizations' response and project alliance contractual complexity was moderated by the mutual goodwill trust.

The findings may have some important practical implications. For the nonequity project alliances in the construction industry, organizations' cultural difference has a significant impact on the selection of partners and project alliance governance. Due to the area characteristics of the construction industry, it is more difficult to adjust the organizational culture based on a certain rule. When the partners have more differences in their organizational cultures, they have to adopt complex alliance contracts, leading to more costs of implementing a contract. Therefore, when the firms seek to form project alliance, the management should consider the organizational cultural differences among the partners. The firms with more significant differences in organizational cultures may not be appropriate to be selected as the alliance partners. If they have selected the partners, the firms need to recognize the level of organizational cultural differences and then determine the proper contractual complexity of the project alliance.

Furthermore, the direct effect and moderator role of the mutual goodwill trust needs to be considered in the context of Chinese construction project. The existence of "Guanxi" implies that the mutual goodwill trust plays an important role in the Chinese business environments. Higher level of mutual goodwill trust among alliance partners may reduce the impact of organizations' response difference on contractual complexity, thus reducing the alliance contractual costs. The establishment of mutual goodwill trust between alliance partners will not only reduce the costs of making contracts but also the costs of implementing the contracts.

While the results of this research help to understand the effect of organizational cultural differences and mutual trust on contract management of nonequity construction project alliances, several limitations are noteworthy. First, the generalizability of the findings may need to be calibrated considering the context of China-based data collection in this research. The data were collected from nonequity project alliances in the construction industry in China. Therefore, the conclusions of this study may have difficulties to be generalized to other population (e.g., equity alliances, other industries, and other countries). It is suggested that, in future studies, the research methods and procedures of this study could be repeated in other contextual backgrounds such as different countries and industries and to test the framework of this research to reach a more generalizable conclusion. Next, the organizational culture, contractual complexity, and mutual trust that we have observed represent the status of a particular time. However, these variables may have changes with time. In a future study, the dynamic changing process of the variables may be investigated.

\section{Conflicts of Interest}

The authors declare that there are no conflicts of interest regarding the publication of this paper.

\section{Acknowledgments}

This research was funded by Research on the Philosophy and Social Sciences Planning Projects of Chongqing, China (Grant no. 2014BS022).

\section{References}

[1] Y. Rezgui and J. Miles, "Exploring the potential of SME alliances in the construction sector," Journal of Construction Engineering and Management, vol. 136, no. 5, pp. 558-567, 2010.

[2] O. E. Williamson, The Economic Institutions of Capitalism: Firms, Markets, Relational Contracting, Free Press, New York, NY, USA, 1985.

[3] D. N. Sillars and R. Kangari, "Japanese construction alliances," Journal of Construction Engineering and Management, vol. 123, no. 2, pp. 146-152, 1997.

[4] J. Ross, "Introduction to project alliancing," in Proceedings of the Alliance Contracting Conference, Project Control International Pty. Ltd., Sydney, NSW, Australia, April 2003.

[5] T. T. Cobianchi, "Relationships among strategic alliance factors and strategic alliance success," Doctoral dissertation, United States International University, College of Business Administration, San Diego Campus, pp. 177-184, 1994.

[6] Y. L. Doz, "The evolution of cooperation in strategic alliances: initial conditions or learning processes?," Strategic Management Journal, vol. 17, no. 1, pp. 55-83, 1996.

[7] P. Lu, S. Guo, L. Qian, P. He, and X. Xu, "The effectiveness of contractual and relational governances in construction 
projects in China," International Journal of Project Management, vol. 33, no. 1, pp. 212-222, 2015.

[8] M. Suprapto, H. L. Bakker, H. G. Mooi, and M J. Hertogh, "How do contract types and incentives matter to project performance?," International Journal of Project Management, vol. 34, no. 6, pp. 1071-1087, 2016.

[9] A. Wu, Z. Wang, and S. Chen, "Impact of specific investments, governance mechanisms and behaviors on the performance of cooperative innovation projects," International Journal of Project Management, vol. 35, no. 3, pp. 504-515, 2017.

[10] M. G. Colombo, "Alliance form: a test of the contractual and competence perspectives," Strategic Management Journal, vol. 24, no. 12, pp. 1209-1229, 2003.

[11] S. Comino, P. Mariel, and J. Sandonís, "Joint ventures versus contractual agreements: an empirical investigation," Spanish Economic Review, vol. 9, no. 3, pp. 159-175, 2007.

[12] J. J. Reuer and A. Ariño, "Strategic alliance contracts: dimensions and determinants of contractual complexity," Strategic Management Journal, vol. 28, no. 3, pp. 313-330, 2007.

[13] F. Lumineau and D. Malhotra, "Shadow of the contract: how contract structure shapes interfirm dispute resolution," Strategic Management Journal, vol. 32, no. 5, pp. 532-555, 2011.

[14] C. M. Rodriguez, "Emergence of a third culture: shared leadership in international strategic alliances," International Marketing Review, vol. 22, no. 1, pp. 67-95, 2005.

[15] D. Lavie, P. R. Haunschild, and P. Khanna, "Organizational differences, relational mechanisms, and alliance performance," Strategic Management Journal, vol. 33, no. 13, pp. 1453-1479, 2012.

[16] G. J. Zhuang and Y. M. Xi, "Impact of personal guanxi on exercises of power in China marketing channels," Journal of Management Sciences in China, vol. 7, no. 6, pp. 52-62, 2004.

[17] D. H. McKnight, L. L. Cummings, and N. L. Chervany, "Initial trust formation in new organizational relationships," Academy of Management Review, vol. 23, no. 3, pp. 473-490, 1998.

[18] J. Huang, L. N. Luo, and Z. X. Chen, "Empirical research on the user adoption intention of emerging technologies products in the early market," Studies in Science of Science, vol. 30, no. 10, pp. 1573-1578, 2012.

[19] T. K. Das and B. S. Teng, "Between trust and control: developing confidence in partner cooperation in alliances," Academy of Management Review, vol. 23, pp. 491-512, 1998.

[20] T. K. Das and B. S. Teng, "Trust, control, and risk in strategic alliances: an integrated framework," Organization Studies, vol. 22, no. 2, pp. 251-283, 2001.

[21] D. K. Datta, "Organizational fit and acquisition performance: effects of post-acquisition integration," Strategic Management Journal, vol. 12, no. 4, pp. 281-297, 1991.

[22] O. E. Williamson, "Comparative economic organization: the analysis of discrete structural alternatives," Administrative Science Quarterly, vol. 36, no. 2, pp. 269-296, 1991.

[23] E. W. L. Cheng, H. Li, P. E. D. Love, and Z. Irani, "Strategic alliances: a model for establishing long-term commitment to inter organizational relations in construction," Building and Environment, vol. 39, no. 4, pp. 459-468, 2004.

[24] P. E. D. Love, D. Mistry, and P. R. Davis, "Price competitive alliance projects: identification of success factors for public clients," Journal of Construction Engineering and Management, vol. 136, no. 9, pp. 947-956, 2010.

[25] R E. Freeman, Strategic Management: A Stakeholder Approach, Cambridge University Press, Cambridge, UK, 2010.
[26] J. Dyer and K. Nobeoka, "Creating and managing a high performance knowledge-sharing network: the Toyota case," Strategic Management Journal, vol. 21, no. 3, pp. 345-367, 2000.

[27] R. C. Mayer, J. H. Davis, and F. D. Schoorman, "An integrative model of organizational trust," Academy of Management Review, vol. 20, no. 3, pp. 709-734, 1995.

[28] X. Jiang, Y. Li, and S. Gao, "The stability of strategic alliances: characteristics, factors and stages," Journal of International Management, vol. 14, no. 2, pp. 173-189, 2008.

[29] S. S. Lui and H. Y. Ngo, "The role of trust and contractual safeguards on cooperation in non-equity alliances," Journal of Management, vol. 30, no. 4, pp. 471-485, 2004.

[30] X. Jiang, "An Empirical Investigation of the Trustopportunism Relationship: Evidence from Inter-hospital Alliances," Management Review, vol. 24, no. 8, pp. 51-57, 2012.

[31] J. Mohr and R. Spekman, "Characteristics of partnership success: partnership attributes, communication behavior, and conflict resolution techniques," Strategic management journal, vol. 15, no. 2, pp. 135-152, 1994.

[32] A. Parkhe, "Strategic alliance structuring: a game theoretic and transaction cost examination of interfirm cooperation," Academy of Management Journal, vol. 36, no. 4, pp. 794-829, 1993.

[33] S. Beugelsdijk, C. Koen, and N. Noorderhaven, "A dyadic approach to the impact of differences in organizational culture on relationship performance," Industrial Marketing Management, vol. 38, no. 3, pp. 312-323, 2009.

[34] V. Pothukuchi, F. Damanpour, J. Choi, C. C. Chen, and S. H. Park, "National and organizational culture differences and international joint venture performance," Journal of International Business Studies, vol. 33, no. 2, pp. 243-265, 2002.

[35] J. B. Smith and D. W. Barclay, "The effects of organizational differences and trust on the effectiveness of selling partner relationships," Journal of Marketing, vol. 61, no. 1, pp. 3-21, 1997.

[36] P. Kale, H. Singh, and H. Perlmutter, "Learning and protection of proprietary assets in strategic alliances: building relational capital," Strategic Management Journal, vol. 21, no. 3, pp. 217-237, 2000.

[37] A. K. Kohli, B. J. Jaworski, and A. Kumar, "Markor: a measure of market orientation," Journal of Marketing Research, vol. 30, no. 4, pp. 467-477, 1993.

[38] A. Zaheer, B. McEvily, and V. Perrone, "Does trust matter? Exploring the effects of interorganizational and interpersonal trust on performance," Organization science, vol. 9, no. 2, pp. 141-159, 1998.

[39] X. Liu and X. F. Xiang, "The strategy of initial trust and control in the $\mathrm{R} \& \mathrm{D}$ alliance: a study based on China's pharmaceutical industry," Management World, vol. 11, pp. 90-100, 2006.

[40] B. Kogut, "Joint ventures: theoretical and empirical perspectives," Strategic Management Journal, vol. 9, no. 4, pp. 319-332, 1988.

[41] S. Das, P. K. Sen, and S. Sengupta, "Impact of strategic alliances on firm valuation," Academy of Management Journal, vol. 41, no. 1, pp. 27-41, 1998.

[42] K. J. Mayer and N. S. Argyres, "Learning to contract: evidence from the personal computer industry," Organization Science, vol. 15, no. 4, pp. 394-410, 2004.

[43] R. J. David and S. K. Han, "A systematic assessment of the empirical support for transaction cost economics," Strategic Management Journal, vol. 25, no. 1, pp. 39-58, 2004. 
[44] E. Anderson and B. Weitz, "The use of pledges to build and sustain commitment in distribution channels," Journal of Marketing Research, vol. 29, no. 1, pp. 18-34, 1992.

[45] P. K. Lee, A. C. Yeung, and T. C. Edwin Cheng, "Supplier alliances and environmental uncertainty: an empirical study," International Journal of Production Economics, vol. 120, no. 1, pp. 190-204, 2009.

[46] S. Mithas, J. L. Jones, and W. Mitchell, "Buyer intention to use internet-enabled reverse auctions: the role of asset specificity, product specialization, and non-contractibility," MIS Quarterly, vol. 32, no. 4, pp. 705-724, 2008.

[47] K. W. Artz and T. H. Brush, "Asset specificity, uncertainty and relational norms: an examination of coordination costs in collaborative strategic alliances," Journal of Economic Behavior and Organization, vol. 41, no. 4, pp. 337-362, 2000.

[48] A. Akintoye, "Analysis of factors influencing project cost estimating practice," Construction Management and Economics, vol. 18, no. 1, pp. 77-89, 2000.

[49] Y. Feng, "Mathematical models for determining the minimum level of voluntary safety investments for building projects," Journal of Construction Engineering and Management, vol. 141, no. 7, p. 04015015, 2015.

[50] Y. Feng, S. Zhang, and P. Wu, "Factors influencing workplace accident costs of building projects," Safety Science, vol. 72, pp. 97-104, 2015.

[51] G. A. Churchill Jr., "A paradigm for developing better measures of marketing constructs," Journal of Marketing Research, vol. 16, no. 2, pp. 64-73, 1979.

[52] J. C. Nunnally, I. H. Bernstein, and J. M. T. Berge, Psychometric Theory, Vol. 226, McGraw-Hill, New York, NY, USA, 1967.

[53] S. Rahman, “A review of empirical research on Total Quality Management using scale developing methods: an Australian perspective," Total Quality Management, vol. 13, no. 5, pp. 635-649, 2002.

[54] C. Fornell and D. F. Larcker, "Evaluating structural equation models with unobservable variables and measurement error," Journal of Marketing Research, vol. 18, no. 1, pp. 39-50, 1981.

[55] Q. G. Ma, "Several key problems concerning the research of management sciences in China," Management World, vol. 8, pp. 105-115, 2002.

[56] Z. L. Wen, J. T. Hou, and L. Zhang, "A comparison of moderator and mediator and their applications," Acta Psychologica Sinica, vol. 37, no. 2, pp. 268-274, 2005.

[57] D. N. Sillars and R. Kangari, "Predicting organizational success within a project-based joint venture alliance," Journal of Construction Engineering and Management, vol. 130, no. 4, pp. 500-508, 2004. 


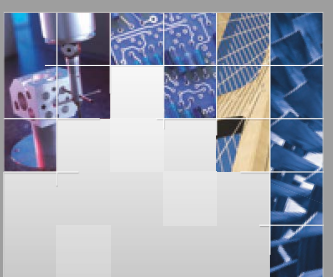

\section{Enfincering}
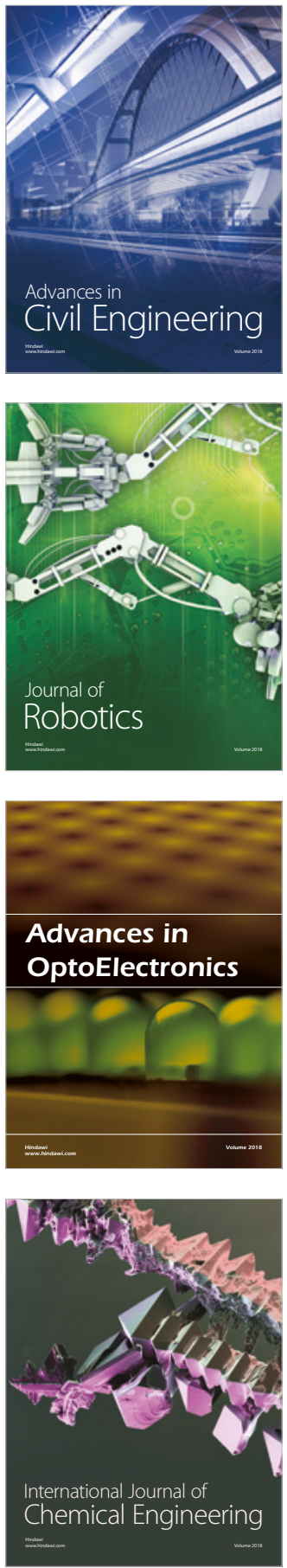

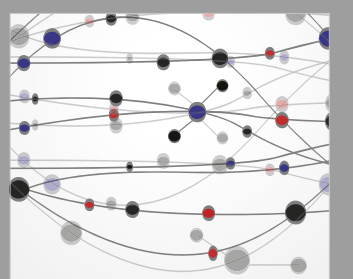

\section{Rotating \\ Machinery}

The Scientific World Journal

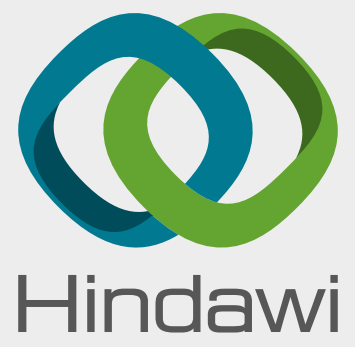

Submit your manuscripts at

www.hindawi.com
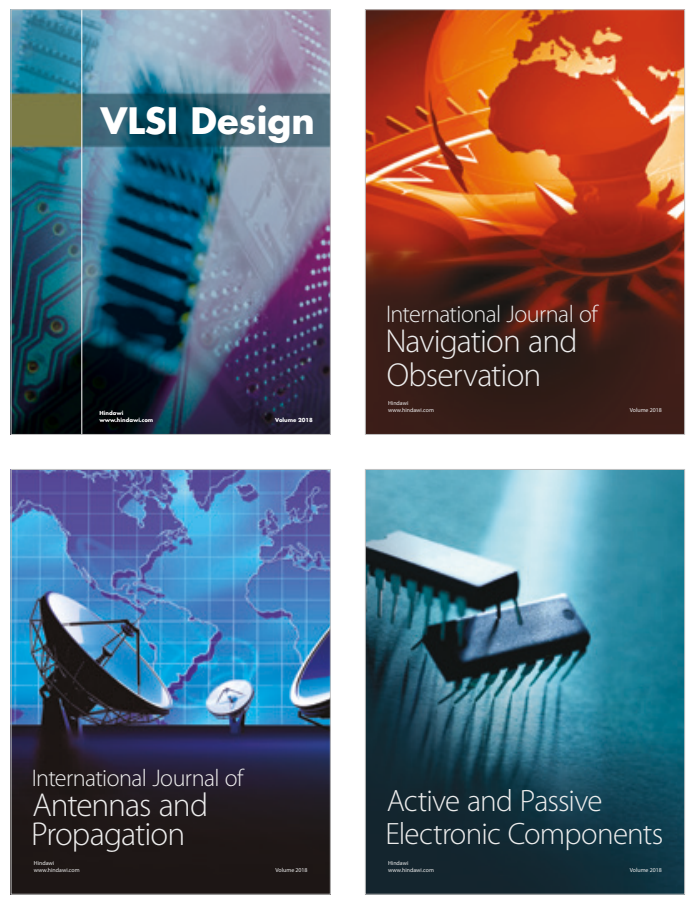
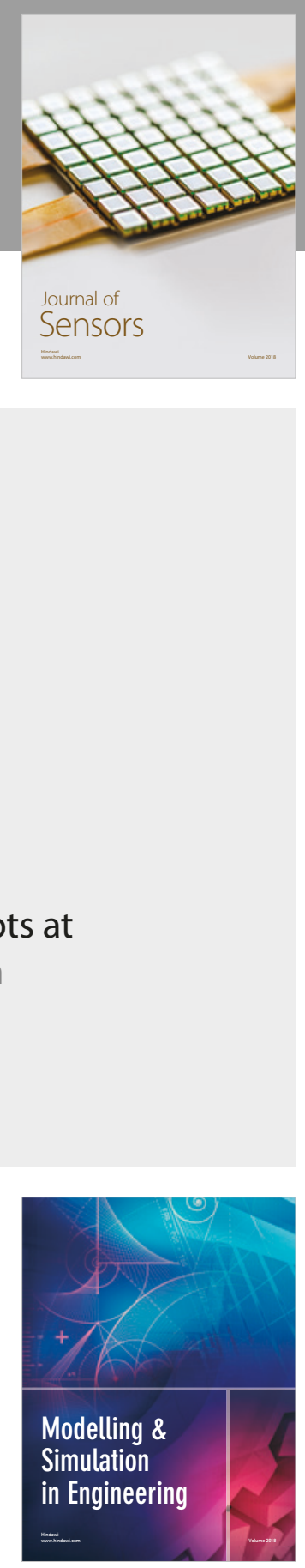

\section{Advances \\ Multimedia}
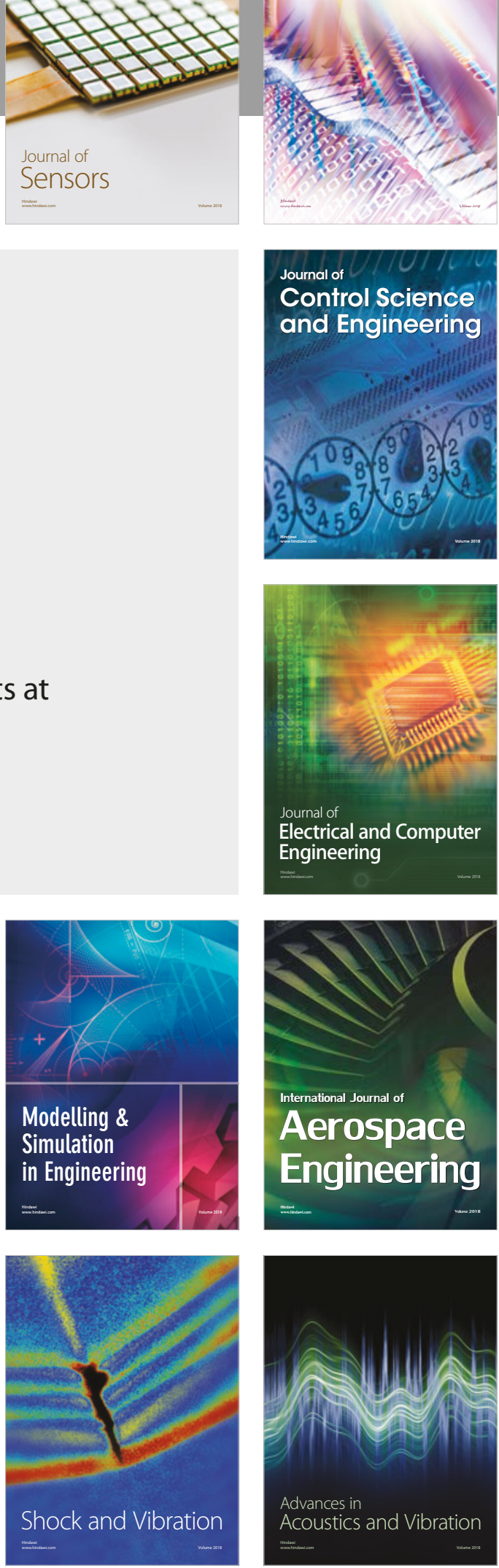